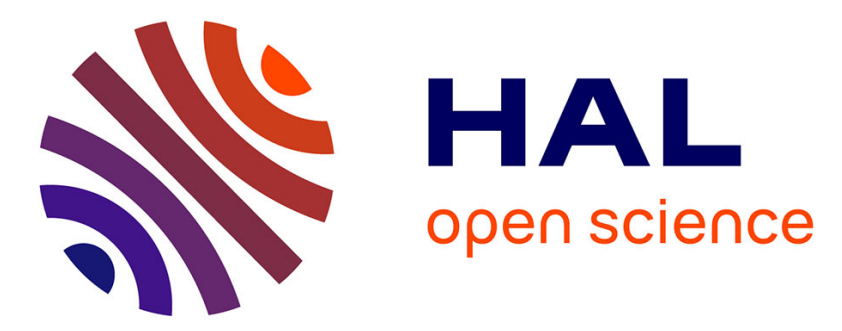

\title{
Anisotropic growth of the thiophene-based layer on $\operatorname{Si}(111)-B$
}

\author{
Alain Rochefort, Younes Makoudi, Arnaud Maillard, Judicaël Jeannoutot, \\ Jacob Blier, Frédéric Cherioux, Frank Palmino
}

\section{To cite this version:}

Alain Rochefort, Younes Makoudi, Arnaud Maillard, Judicaël Jeannoutot, Jacob Blier, et al.. Anisotropic growth of the thiophene-based layer on $\mathrm{Si}(111)-\mathrm{B}$. Chemical Communications, 2014, 50, pp.5484 - 5486. 10.1039/c4cc01674b . hal-00983037

\section{HAL Id: hal-00983037 https://hal.science/hal-00983037}

Submitted on 24 Apr 2014

HAL is a multi-disciplinary open access archive for the deposit and dissemination of scientific research documents, whether they are published or not. The documents may come from teaching and research institutions in France or abroad, or from public or private research centers.
L'archive ouverte pluridisciplinaire HAL, est destinée au dépôt et à la diffusion de documents scientifiques de niveau recherche, publiés ou non, émanant des établissements d'enseignement et de recherche français ou étrangers, des laboratoires publics ou privés. 


\section{ChemComm}

\section{COMMUNICATION}

\section{Anisotropic growth of the thiophene-based layer on $\mathrm{Si}(111)-\mathrm{B} \dagger$}

Cite this: Chem. Commun., 2014,

50,5484

Received 5th March 2014,

Accepted 30th March 2014

DOI: $10.1039 / c 4 c c 01674 b$

www.rsc.org/chemcomm

\author{
A. Rochefort, ${ }^{* a}$ Y. Makoudi, ${ }^{b}$ \\ F. Palmino ${ }^{\text {b }}$
}

The formation of large assemblies on the Si(111)-B surface is discussed with the help of STM simulations and DFT calculations. Although highly regular assemblies of DTB10B along the Si row direction are observed, the existence of two herringbone isomers introduces a lower periodicity within the 2D molecular network. The formation of herringbone units is explained by weak intermolecular interactions while the 1D assembling depends mainly on the interactions of the $C_{10}$ side chains with the Si(111)-B surface.

The adsorption of oligothiophenes on semiconducting surfaces has not often been studied due to their high propensity to form covalent bonds with surface atoms. ${ }^{1,2}$ On the other hand, the use of highly doped Si-surfaces allows, to a certain degree, controlling the reactivity of Si surface atoms. ${ }^{3}$ In contrast, the number of studies on graphite or HOPG surfaces is much more significant. ${ }^{4-6}$ On such weakly reactive surfaces, the structure of adsorbed oligothiophene mostly depends on intermolecular interactions, more especially on the nature and structure of the functional groups attached to the thiophene unit. ${ }^{7,8}$ The size of the molecular units used in these studies is usually quite high, and such studies can rarely benefit from theoretical support by STM simulations. Here, we used a $\mathrm{Si}(111)-\mathrm{B}$ surface $\dagger$ to weaken molecule-substrate interaction in order to achieve the supramolecular network. We demonstrate that STM simulations are becoming practical for large-scale systems, and can be used to support and explain complex surface processes.

Fig. 1 shows that the adsorption of 1,4-bis(5-(2,2'-dithienyl))2,5-bis(decyloxy)benzene $\dagger$ (DTB10B) on Si(111)-B can lead to a large overlayer forming $120^{\circ}$ in-plane orientation (see orange and blue domains). In each domain, the adsorbed molecules adopt a regular herringbone pattern along the indicated lines.

\footnotetext{
${ }^{a}$ Polytechnique Montréal, Engineering Physics Department and Regroupement québécois sur les matériaux de pointe (RQMP), Montréal, Canada. E-mail: alain.rochefort@polymtl.ca

${ }^{b}$ Institut FEMTO-ST, Université de Franche-Comté, CNRS, ENSMM, 32 Avenue de l'Observatoire, F-25044 Besancon, France

$\dagger$ Electronic supplementary information (ESI) available. See DOI: 10.1039/ c4cc01674b
}

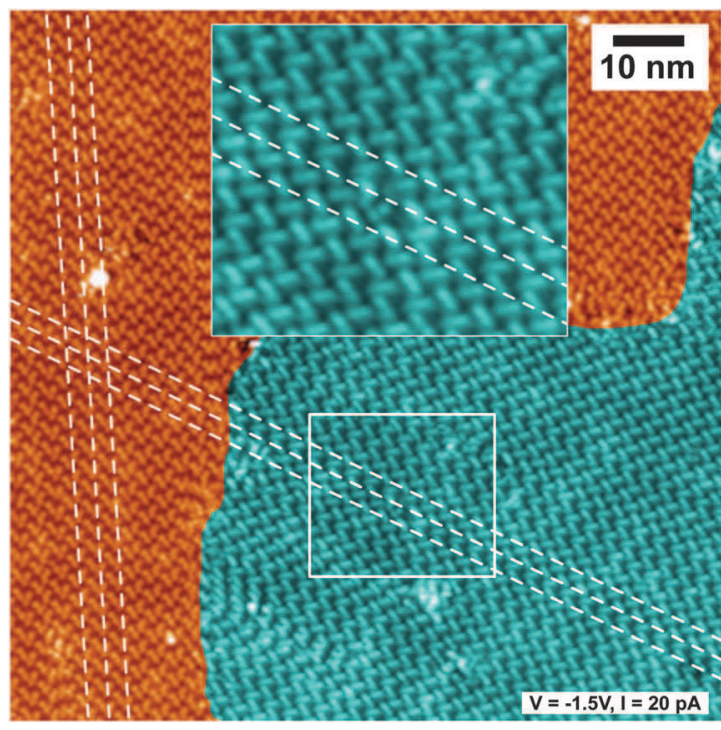

Fig. 1 STM image of the organization of DTB10B molecules on the Si(111)-B surface at high coverage.

Such periodicity is not totally conserved in the molecular $2 \mathrm{D}$ network, where the herringbone units are irregularly shifted from one line to the other. From the size of this STM image, we estimate that the molecular network domains may extend over $100 \times 100 \mathrm{~nm}^{2}$. We want to emphasize that for a given direction (see dashed lines), the herringbone units are without exception aligned in that unique direction.

In order to understand the influence of the $\mathrm{Si}(111)-\mathrm{B}$ substrate on the overlayer growth, Fig. 2A shows an STM image near the edge where Si-adatoms can be easily identified in the upper part of the image. We can clearly see that the alignment of the molecules observed in Fig. 1 follows exceptionally well the Si-adatom corrugation of the $\mathrm{Si}(111)-\mathrm{B}$ surface. In addition, this figure also reveals that a series of well-defined Si-adatom rows are separated by an angle of $60^{\circ}$.

A more careful analysis of the STM features can be performed in Fig. 2. According to the molecular lengths shown in 


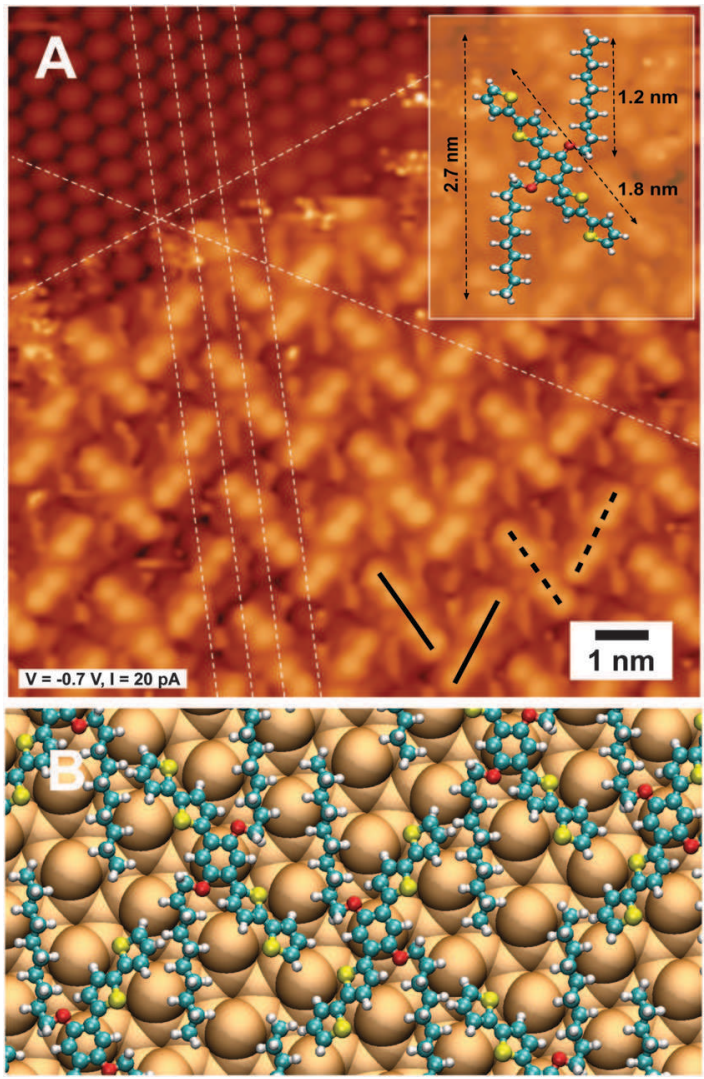

Fig. 2 (A) STM image of the DTB10B/Si(111)-B near overlayer edge. Si adatom rows are identified by white dashed lines. The two types of herringbone dimers are indicated by the black lines. The inset gives the structural parameters of the isolated DTB10B molecule. (B) Adsorption model of a well-ordered DTB10B/Si(111)-B network.

the inset of Fig. 2A, the core of DTB10B containing the oligothiophene fragment corresponds to the brightest STM features composed of four protuberances well separated by a lower contrast region in the middle. The aliphatic $\mathrm{C}_{10}$ side chains are revealed in STM through less intense but linear features on both sides of the DTB10B core. More importantly, these side chains are well-aligned along the Si-adatom row direction (see white dashed lines) and are invariably located between Si-adatom rows. This result strongly suggests that the $\mathrm{C}_{10}$ chains play a major role in the orientation of the DTB10B units. From the STM contrasts in this well-organized region, an adsorption model shown in Fig. 2B can be proposed.

Following the STM simulations approach developed by Boulanger-Lewandowski and Rochefort ${ }^{9}$ on large atomic models, we used a finite model containing about 6600 atoms as a starting point of our STM simulations. $\dagger$ The advantage of this approach is the possibility to consider independent structural modifications within the assembled layer without imposing a spatial periodicity in the calculations. For simplicity, we used a periodic DTB10B network, a Hamiltonian based on the extended Huckel method, and the STM image was obtained at the Tersoff-Hamann level of theory. Instead of focusing on the more stable adsorbed phase at $0 \mathrm{~K}$ resulting from a nearly impractical DFT calculation in the present case, we rather
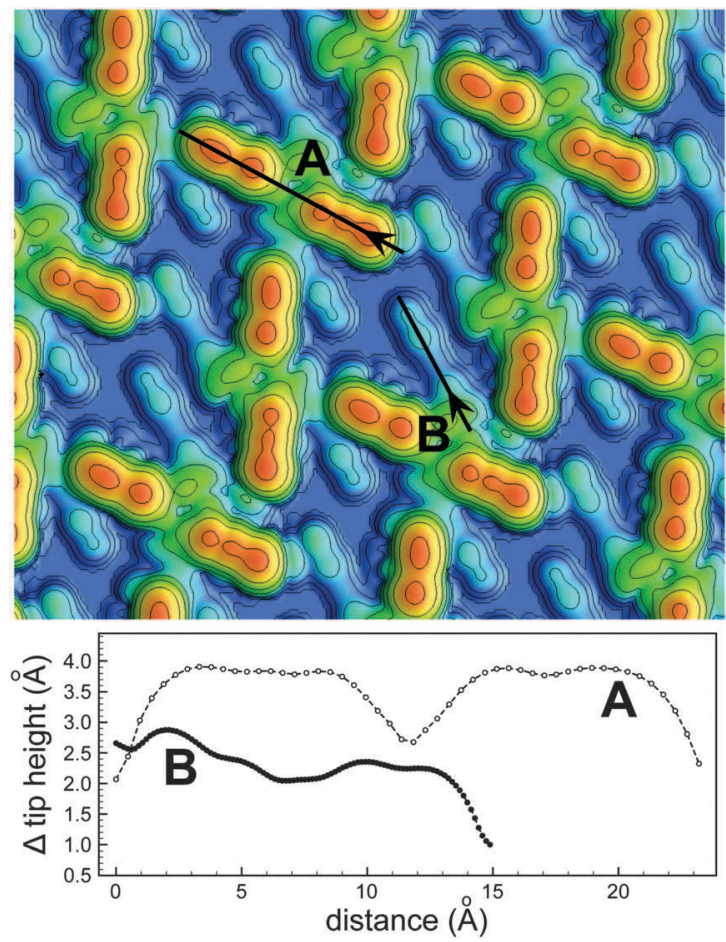

Fig. 3 Simulated STM image (upper panel) obtained at the TH level $(V=-1.5 \mathrm{eV}, I=0.1 \mathrm{nA})$, and variation of the calculated tip height (lower) along the $\mathrm{A}$ and $\mathrm{B}$ pathways reported in the upper panel.

introduced appropriate structural modifications in the adsorption model to reproduce experimental STM features. Since the orientation of the $\mathrm{C}_{10}$ chains on the substrate is clear, we have concentrated our effort on the geometry of the oligothiophene core. We found an excellent agreement between experimental (Fig. 2) and simulated STM (see Fig. 3) images when the four thiophene units are rigidly rotated by around $35^{\circ}$ with respect to the more central benzene ring that appears totally flat, such as the $\mathrm{C}_{10}$ chains, on the $\mathrm{Si}(111)-\mathrm{B}$ surface.

The description of the experimental STM image given above is totally consistent with our STM simulations shown in Fig. 3. The upper part of Fig. 3 shows a calculated STM image of a wellorganized DTB10B overlayer where the $\mathrm{C}_{10}$ chains are located between Si-adatom rows and aligned along the direction of these rows. As observed experimentally, the molecular core appears as four bright protrusions and the side chains located on both sides of the core are less intense. As reported in the lower panel, we analyzed the profile of the STM image along the A and B straight lines. We distinguish the presence of the protrusion associated with the DTB10B core and with the depletion of conducting states in the more central region. Along the B pattern, the highest height near $2 \AA$ is due to the presence of oxygen atoms on which the $\mathrm{C}_{10}$ side chains are attached. Otherwise, the lengths of the calculated profiles are in excellent agreement with the size of the molecule reported in the inset of Fig. 2. The geometry of the adsorbed phase proposed from STM simulations is also consistent with the results of DFT/B3LYP/6-31G calculations performed on the isolated DTB10B molecule. $\uparrow$ Ground state geometry of DTB10B 

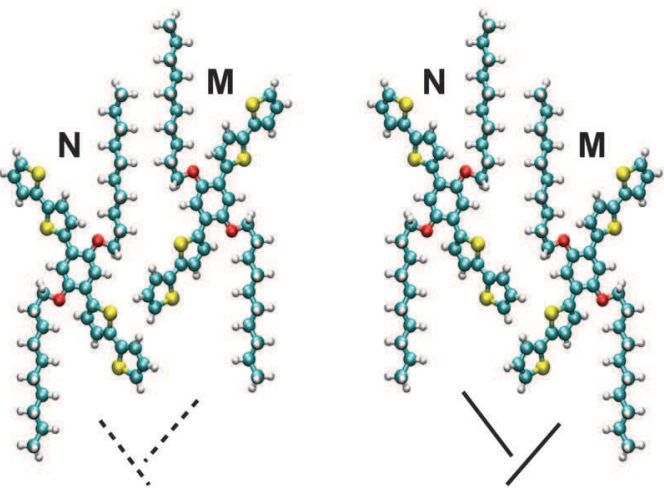

Fig. 4 Structural arrangement of DTB10B molecules forming two isomers of a herringbone dimer.

shows that $\mathrm{C}_{10}$ chains are not flat with respect to the oligothiophene core but are twisted by around $50^{\circ}$. Since STM reveals that the $\mathrm{C}_{10}$ chains lie on the $\mathrm{Si}(111)-\mathrm{B}$ surface in the adsorbed phase, including the more central benzene core, the thiophene units need to rotate in order to minimize steric repulsion with the $\mathrm{C}_{10}$ chains that become flatter. This forced planarization should provoke the tilting of all thiophene units in a unique direction. This geometry agrees with the profiles calculated in Fig. 3, where the bright protrusions are well-aligned rather than forming a zig-zag shape as it is the case when the thiophene units are independently rotated from one to the others (see S4, ESI $\dagger$ ).

We now turn to the formation of the DTB10B network. A systematic alignment of DTB10B dimers and $\mathrm{C}_{10}$ side chains along the direction of Si-adatom rows is observed, but we do not recover a similar periodicity in the $2 \mathrm{D}$ overlayer, which shows several defects. For example, the two herringbone arrangements identified by full and dashed black lines in Fig. 2A contribute to break this 2D network periodicity. It is also very interesting to note that molecules that form herringbones are flipped by $180^{\circ}$ from one to the other. Statistically, the adsorption of DTB10B should equally lead to two different adsorbed species $(\mathrm{N}, \mathrm{M})$, one being the mirror image of the other. Although the observed herringbone dimers have different arrangements, they are strictly formed from an N-M pair. First, the large proportion of herringbone dimers in the network strongly suggests that DTB10B molecules form herringbone dimers that diffuse, and assemble along the 1D direction of Si-adatoms under the influence of the interaction of the $\mathrm{C}_{10}$ chains with the surface. Second, the presence of two different herringbone dimers can be explained by weak interactions such as $\mathrm{CH}-\pi$ attraction ${ }^{10}$ between DTB10B units. As the thiophene units are rotated, isomers of the DTB10B dimer are proposed in Fig. 4, where the black lines give the thiophene core position (see also Fig. 2A). In principle, the proportion of both herringbone isomers should be nearly equal, and once a dimer is assembled within the $1 \mathrm{D}$ direction, the periodicity in the $2 \mathrm{D}$ direction will only depend on the type of isomer that will adsorb in the next 1D assembly. Although a more quantitative description of the elementary adsorption steps would need additional experimental and theoretical efforts, a simple analysis of gas phase species and STM simulations can provide vital structural information of adsorbed phases.

In conclusion, experiments reveal that adsorption of DTB10B is dominated by the anisotropic interaction of the $\mathrm{C}_{10}$ chains with $\mathrm{Si}(111)-\mathrm{B}$. Supported by STM simulations, we showed that weak intermolecular interactions such as $\mathrm{CH}-\pi$ bonding direct the orientation of DTB10B in the formation of a herringbone dimer. Hence, the adsorption of DTB10B is highly periodic in one direction but not in the $2 \mathrm{D}$ direction.

This work was supported by NSERC, MDER, Nano-Québec, ANR (Nanokan, ANR-11-BS10-004) and by the Pays de Montbéliard agglomération. We are grateful to Calcul Québec and Calcul Canada for providing computational facilities.

\section{References}

1 Y. Cao, K. S. Yong, Z. H. Wang, J. F. Deng, Y. H. Lai and G. Q. Xu, J. Chem. Phys., 2001, 115, 3287.

2 N. Isobe, T. Shibayama, Y. Mori, K. Shobatake and K. Sawabe, Chem. Phys. Lett., 2007, 443, 347.

3 (a) B. Baris, V. Luzet, E. Duverger, P. Sonnet, F. Palmino and F. Chérioux, Angew. Chem., Int. Ed., 2011, 50, 4094; (b) B. Baris, J. Jeannoutot, V. Luzet, F. Palmino, A. Rochefort and F. Chérioux, ACS Nano, 2012, 6, 6905; (c) S. R. Wagner, R. R. Lunt and P. Zhang, Phys. Rev. Lett., 2013, 110, 086107.

4 M. Linares, L. Scifo, R. Demadrille, P. Brocorens, D. Beljonne, R. Lazzaroni and B. Grevin, J. Phys. Chem. C, 2008, 112, 6850.

5 M. Bonini, L. Zalewski, E. Orgiu, T. Breiner, F. Dötz, M. Kastler and P. Samori, J. Phys. Chem. C, 2011, 115, 9753.

6 R. Gutzler, C. Fu, A. Dadvand, Y. Hua, J. M. MacLeod, F. Rosei and D. F. Perepichka, Nanoscale, 2012, 4, 5965.

7 I. F. Perepichka and D. F. Perepichka, Handbook of Thiophene-Based Materials: Applications in Organic Electronics and Photonics, John Wiley \& Sons, 2009.

8 E. Mena-Osteritz, M. Urdanpilleta, E. El-Hosseiny, B. Koslowski, P. Ziemann and P. Bäuerle, Beilstein J. Nanotechnol., 2011, 2, 802.

9 N. Boulanger-Lewandowski and A. Rochefort, Phys. Rev. B: Condens. Matter Mater. Phys., 2011, 83, 115430.

10 E. R. T. Tiekink and J. Zukerman-Schpector, The Importance of Pi-Interactions in Crystal Engineering: Frontiers in Crystal Engineering, John Wiley \& Sons, 2012. 